\title{
Determinants of caregiver burden of persons with disabilities in a rural district in Egypt
}

\author{
Eman Ramadan Ghazawy, Eman Sameh Mohammed, Eman Mohamed Mahfouz and Marwa Gamal Abdelrehim*
}

\begin{abstract}
Background: Family caregivers are critical partners in the plan of care of people with disabilities. The study aims to demonstrate the factor structure and internal consistency of the Caregiver Burden Inventory (CBI) among the studied caregivers of disabled persons and to determine the effects of patients' and caregivers' characteristics on the burden and its dimensions.

Methods: A cross-sectional study among 260 family caregivers of disabled patients was carried out in a randomly chosen rural area, Minia, Egypt, 2019. Exploratory factor analysis (EFA) was conducted to determine the factorial validity of the CBI. Multiple linear regression was used to identify the significant factors affecting the burden.

Results: Factor analysis resulted in a five-factor solution using 20 items (four for each dimension) accounting for $72.7 \%$ of the total variance. The CBI and its dimensions showed high internal consistency (Cronbach's alpha value > 0.70). Education of caregiver, family income, mental impairments, and mixed disabilities were significant predictors of total CBI burden.

Conclusions: $\mathrm{CBI}$ is an effective multidimensional measure of the caregiver burden of disabled subjects. Caregivers experienced a distinct level of burden that is determined by caregiver and care recipient characteristics. Therefore, support and individualized counseling services should be optimized.
\end{abstract}

Keywords: Caregivers, Burden, Disabled, Exploratory factor analysis, Egypt

\section{Background}

Disability is a dynamic, multidimensional, and diverse public health issue of increasing importance and rising trend [1]. People with a disability have been defined by The UN Convention on the Rights of Persons with Disabilities (UNCRPD) as those who have a long-term physical impairment which is the most common type, mental, intellectual or sensory impairments which in interaction with various barriers may hinder their full and effective participation in the society on an equal basis with the others [2]. Disability may be temporary

* Correspondence: marwa.gamal@mu.edu.eg; marwagamal_84@yahoo.com Department of Public Health and Preventive Medicine, Faculty of Medicine, Minia University, Minia, Egypt due to acute disease, and/or injury, or chronic; and it may arise as a congenital condition or acquired later in life [3]. People with disabilities are one of the most disadvantaged, marginalized, and excluded population groups in terms of employment, educational attainment, access to adequate services as well as social participation and individual autonomy [4].

Disability rates are increasing due to many factors such as wars, aging population, increasing poverty and illiteracy, upward rise in chronic health conditions, and weakness of infrastructure of services [5]. Globally, people who live with some form of disability constitute approximately $15 \%$ or an estimated 1 billion people [1]. In Egypt, disability rates are reported to be very low

(c) The Author(s). 2020 Open Access This article is licensed under a Creative Commons Attribution 4.0 International License, which permits use, sharing, adaptation, distribution and reproduction in any medium or format, as long as you give appropriate credit to the original author(s) and the source, provide a link to the Creative Commons licence, and indicate if changes were made. The images or other third party material in this article are included in the article's Creative Commons licence, unless indicated otherwise in a credit line to the material. If material is not included in the article's Creative Commons licence and your intended use is not permitted by statutory regulation or exceeds the permitted use, you will need to obtain permission directly from the copyright holder. To view a copy of this licence, visit http://creativecommons.org/licenses/by/4.0/. The Creative Commons Public Domain Dedication waiver (http://creativecommons.org/publicdomain/zero/1.0/) applies to the data made available in this article, unless otherwise stated in a credit line to the data. 
(0.7\% of the total population) [6] which are much lower than the international data-sets [7]. Thus, the figures seem unrealistic and inconclusive. This may be due to the method of data collection, starting with the understanding or definition of disability, the method of data collection, and/or societal or cultural attitudes (e.g. tending to hide disability in public). The major causes of disability in Egypt are congenital abnormalities, followed by injuries/accidents, old age, epidemics, and other diseases, and birth-related conditions [8].

Disability does not only affect the person who is disabled but also has an impact on the entire family because disabled persons require help in performing their daily activities and in managing medications $[9,10]$. Parents, especially mothers, take on the responsibility as primary caregivers helping disabled individuals in maintaining their community connections [11]. The challenges faced by the caregivers are known as the "caregiver burden" which was described as a feeling of heavy responsibility, constant worries, and uncertainty about patients' needs and constraints in caregivers' social life [12]. As the burden increases, caregivers may be subjected to physical and mental health problems, financial burdens, disturbance in family life, and it may end with the loss of control especially if they do not receive adequate training, guidance, and support [13]. Moreover, caregivers tend to place a low priority on their own health compared to the time and effort they spend in caring for disabled members [14]. Consequently, their quality of life may be compromised especially with increasing duration, the severity of illness, and negative feelings associated with caregiving such as self-blame, guilt, shame, and embarrassment [15].

Although caregiver burden has been measured in a variety of ways [16-18], the Caregiver Burden Inventory (CBI) is a multidimensional scale aimed to assess the impact of the burden on different aspects of a caregiver's life, including caregiver's well-being and function which may be differentially affected by the relative's disability. The CBI conceptualizes the burden in terms of five categories (time dependency, emotional health, physical health, development, and social relationships) [19].

Data on the prevalence of disability in Egypt are inconclusive and do not accord with international data-sets. However, the few available data suggest a high and unmet need for health-related rehabilitation [8], which may increase the burden of care for their families. Many researches have investigated the impact of disability on the persons affected, but there is a paucity of data regarding caregiver burden especially in Upper Egypt. Additionally, short term respite programs are extremely limited in rural Egypt despite the rapidly increasing demands for home services. Consequently, family members bear the heavy responsibilities and stress associated with providing appropriate care and supervision to their disabled relatives. Neglect and inadequate care are more common when the caregiver is burdened leading to deterioration in the patient's health status which indicates and predicts the caregiver's breaking point. Ensuring a healthy unburdened caregiver is important to secure patient safety and care effectiveness. So, this research provides an insight into this burden which may help service providers to develop new strategies to support caregivers in their role. The purpose of this study is to demonstrate the factor structure and internal consistency of the CBI to be used among caregivers of disabled persons in Minia, Egypt and to determine the associations of caregiver burden and its different dimensions with various care recipients' and caregivers' characteristics.

\section{Methods}

\section{Study design and setting}

A community-based cross-sectional study was conducted from September to November 2019 in a rural area (Nazlet El-falahin) which was randomly chosen among all 40 villages of Minia district, Egypt. The data were collected in two phases. Firstly, a list of households with disabled individuals was obtained from both the health office of the village and the non-governmental organization for the disabled support in the region. Appropriate verification of the disability state was done by contacting the households and/or the health center of the village for documentation of impairment in the form of a hospital document, physician statement, or investigation report. In case of not providing a document for a disability, the household was excluded from the list. Secondly, the study sample was recruited via a systematic random sampling technique. The first house was chosen randomly then every second house was visited in a randomly selected direction and the houses which were locked at the time of the survey were revisited on three consecutive days before excluding from the study.

\section{Study population and data collection}

The participants were family caregivers of adolescent and adult disabled patients. Disabled persons included subjects who had been previously diagnosed to have any of the following; blindness/low vision, hearing impairment, physical disability, mental illness, and mixed impairments. The physical impairment substantially limits the person's physical functioning, mobility, dexterity, or stamina. While a mental disability includes intellectual, speech or learning disabilities, mental or psychological disorder, and chronic neurological conditions that substantially limits one or more major life functions. Caregivers were recruited on the basis of the following criteria: a) caregivers of people aged $\geq 10$ years with any type of disability; b) primary caregivers; as persons who 
adopting functions of care and supervision in basic daily activities of the disabled person c) giving care to the patient for at least 6 months; d) aged 18 years or more. Those who were paid in return for caregiving service; were excluded from this study. Among the total 260 primary caregivers eligible for the study, 17 refused to participate giving a response rate of $93.5 \%$. Each participant was interviewed during a home visit, the aim of the study was explained and the answers to the questionnaire were filled in by the researcher.

Data collection tools included the following:

\section{A structured interview questionnaire:}

Interviews took place in the caregiver's home. The questionnaire covered socio-demographic characteristics of both the caregiver and care recipient, the nature of the relationship with care recipients, type of disability, and the duration of caregiving/year.

\section{Caregiver burden:}

The caregiver burden was assessed using the Caregiver Burden Inventory (CBI) developed by Novak and Guest [19]. It is a 24-item multi-dimensional questionnaire measuring caregiver burden with five subscales: (a) Time Dependence; (b) Developmental; (c) Physical Burden; (d) Social Burden; (e) Emotional Burden. All dimensions contain five items with a 5-point Likert scale except Physical Burden which is based on four items. Briefly, time dependence burden evaluates stress caused by the restriction of one's personal time due to time demands of caregiving whereas developmental burden describes a sense of failure in development with respect to their peers. Physical burden refers to the impact on caregivers' physical health, strength, and energy while social burden implies feelings of role conflict concerning one's job or family. Finally, emotional burden represents negative feelings, embarrassment or feeling of shame caused by the patient [19].

\section{Statistical analysis}

Statistical analysis was carried out using IBM SPSS Statistics, version 22. Characteristics of caregivers and care recipients were expressed by mean \pm standard deviation for continuous variables and as a percentage for categorical variables. In order to determine the factorial validity of the CBI among the study population, an exploratory factor analysis (EFA) was conducted using principal axis factoring. An oblique rotation using direct oblimin was implemented. Kaiser-Meyer-Olkin (KMO) measure of sampling adequacy and Bartlett's Test of Sphericity were conducted to indicate that EFA was appropriate. The number of factors was determined according to: 1) eigenvalue $>1 ; 2$ ) a scree plot; 3) the percent of variance extracted, and; 4) the interpretability of the extracted factors in the context of the research. A factor loading > 0.32 for a variable was used to be considered adequately loaded on a factor. Cronbach's alpha coefficient was used to assess the internal consistency of the scales and alpha coefficients equal to or greater than 0.70 were considered to be satisfactory.

Bivariate associations between dimensions of burden and patients' and caregivers' characteristics were examined by student $\mathrm{t}$-test and ANOVA. Multiple linear regression analysis was used to identify the significant factors that affect the level of caregivers' burden. The level of statistical significance was set at $P<0.05$.

\section{Results}

\section{Sample description}

The characteristics of the participants were shown in Table 1. Most of the caregivers were females (87.7\%), married subjects $(80.7 \%)$, and illiterates (58\%). The mean age of caregivers was $43.6 \pm 12.8$ years and only $14 \%$ of them had a paid job. Most of the participants consist of parents (62.6\%) of the disabled person, and the duration of caregiving ranged from 1 year to 40 years with a mean of $14.3 \pm 9.9$ years. About one third $(n=90 ; 37 \%)$ of the sample reported a worsening in their economic level. The mean age of care recipients was $31.7 \pm 18.8$, and $73.3 \%$ were males. Of the 243 care recipients, 141 (58\%) suffered from physical disabilities.

\section{Exploratory factor analysis}

The EFA results in a five-factor solution accounting for $72.7 \%$ of the total variance (Table 2).

Unlike the original CBI which had five items in each dimension except the physical one (that had four items), and was originally supported by Caserta et al. [20] who examined the multidimensional nature of $\mathrm{CBI}$, the current study showed four items with significant loadings on each retained factor. Item 2 ("My care receiver is dependent on me"), item 8 ("My social life has suffered"), item 18 ("I don't do as good a job at work as I used to") and item 22 ("I resent my care receiver") were excluded during the analysis because they consistently load $>0.32$ across major factors after various oblique rotations and solutions. Each extracted factor contains four items, with a scoring system ranging from 0 (minimum stress) to 4 (maximum stress). The score for each factor was calculated by multiplying the sum of items by 1.25 so that the scores for all factors can range from zero to 20 and the total score from zero to 100 to be comparable with previous studies.

The CBI scale and its dimensions proved to be very reliable (Cronbach's alpha value for the total scale, physical, time dependence, developmental, emotional, and 
Table 1 Socio-demographic characteristics of the caregivers and related care recipients

\begin{tabular}{|c|c|c|}
\hline \multirow{2}{*}{$\begin{array}{l}\text { Socio-demographic } \\
\text { characteristics }\end{array}$} & \multirow{2}{*}{$\begin{array}{l}\text { Caregivers } n=243 \\
N(\%)\end{array}$} & \multirow{2}{*}{$\begin{array}{l}\text { Care recipient } n=243 \\
N(\%)\end{array}$} \\
\hline & & \\
\hline Age (mean \pm SD) & $43.6 \pm 12.8$ & $31.7 \pm 18.8$ \\
\hline $10-<18$ years & - & $66(27.2)$ \\
\hline 19-40 years & $103(42.4)$ & $119(49.0)$ \\
\hline $41-60$ years & $116(47.4)$ & $30(12.3)$ \\
\hline$>60$ years & $24(9.9)$ & $28(11.5)$ \\
\hline \multicolumn{3}{|l|}{ Sex } \\
\hline Male & $30(12.3)$ & $178(73.3)$ \\
\hline Female & $213(87.7)$ & $65(26.7)$ \\
\hline \multicolumn{3}{|l|}{ Marital status } \\
\hline Married & $196(80.7)$ & $73(30.0)$ \\
\hline Unmarried & $47(19.3)$ & $170(70.0)$ \\
\hline \multicolumn{3}{|l|}{ Working status } \\
\hline Not working & $209(80)$ & $207(85.1)$ \\
\hline Working & $34(14)$ & $36(13.9)$ \\
\hline \multicolumn{3}{|l|}{ Education } \\
\hline Illiterate & $141(58)$ & $122(50.2)$ \\
\hline Primary & $34(14)$ & $64(26.3)$ \\
\hline Secondary/ University & $68(28)$ & $57(23.5)$ \\
\hline \multicolumn{3}{|l|}{ Relationship to the patient } \\
\hline Parent & $152(62.6)$ & - \\
\hline Spouse/partner & $36(14.8)$ & \\
\hline Sibling & $26(10.7)$ & \\
\hline Other relatives & 29 (11.9) & \\
\hline Duration of caregiving & $14.3 \pm 9.9$ & - \\
\hline \multicolumn{3}{|l|}{ Type of disability } \\
\hline Visual/ hearing & & $50(20.6)$ \\
\hline Physical & & $91(37.4))$ \\
\hline Mental & & $61(25.1)$ \\
\hline Mixed & & $41(16.9)$ \\
\hline
\end{tabular}

social burden were $0.93,0.91,0.84,0.91,0.85$ and 0.77 respectively).

\section{Relationship of dimensions of burden and caregiver's characteristics}

The mean score of CBI for the caregivers was $48.9 \pm$ 17.9. Among the five dimensions of burden, the timedependent burden scored the highest $(13.1 \pm 5)$ followed by physical burden $(9.9 \pm 4.9)$. Developmental and social burden scored $(9.1 \pm 4.8$ and $8.9 \pm 4.1$ respectively) while emotional burden $(7.9 \pm 4.2)$ had the lowest scores. The caregiver's characteristics were associated with caregiver burden as shown in (Table 3 ). Caregivers aged $>60$ years old had significantly higher physical and time dependence burden (13.4 \pm 4.5 and $15.5 \pm 6.5)$ compared to younger age groups. Non-educated caregivers had higher scores for total burden and its dimensions except the emotional burden. Moreover, low family income was associated with higher burden scores.

Spouses of patients had significantly higher scores than other related groups; $(10.8 \pm 5.1)$ for physical; $(8.5 \pm 4.6)$ for emotional; $(9.8 \pm 4.4)$ for social and $(51.5 \pm 19.2)$ for total burden. Caregiving for more than 10 years was associated with significantly higher physical and social burden scores $(10.7 \pm 7.1$ and $9.6 \pm 4.3)$ compared to caregiving for $\leq 10$ years $(9.1 \pm 4.7$ and $8.2 \pm 3.8)$, respectively. The five dimensions and the total scores for CBI were not significantly associated with caregiver sex, marital status, or employment status $(P>0.05)$.

\section{Relationship of dimensions of burden and care recipient's characteristics}

Of the demographic factors of care recipients associated with the burden of care, caring for male patients was significantly associated with higher social burden $(9.3 \pm 4.2)$ compared to caring for females $(7.9 \pm 3.7)$. The type of disability was significantly associated with the caregiver's total burden and its five dimensions' scores; those who care for patients with mixed disabilities had higher scores in the total CBI and all dimensions of burden (Table 4).

\section{Multivariate regression for factors associated with caregiver burden}

The multivariable-adjusted linear regression models (Table 5) showed that: (i) Education of caregiver, family income, mental and mixed disabilities were the significant predictors of the total CBI and developmental burden (20.3 and $18.5 \%$ of variance explained) respectively. The beta, coefficients of mental and mixed disabilities of care recipients were the highest for the total burden (11.82 and 13.74 respectively). (ii) Family income was a significant predictor of the total CBI and most dimensions, while the relationship to a patient was the only significant predictor of social burden. (iii) Having mental and mixed disabilities were the only significant predictors of emotional burden (18.5\% of variance explained), while caregiver age and family income represented the significant predictors of physical burden $(13.7 \%$ of variance explained). (iv) Perceived lower time-dependence burden was associated with family income and care recipient characteristics as being educated, working patients, younger age, and patients with visual or hearing impairments ( $15.4 \%$ of variance explained).

\section{Discussion}

Evaluation of the burden of care of a person with a disability is an important aspect of the patient's overall assessment. The study supports the evidence that most 
Table 2 Factor Structure for the dimensions of $C B$

\begin{tabular}{|c|c|c|c|c|c|}
\hline Items of $\mathrm{CBI}$ & $\begin{array}{l}\text { Factor 1: } \\
\text { Physical } \\
\text { burden }\end{array}$ & $\begin{array}{l}\text { Factor 2: Time } \\
\text { dependence } \\
\text { burden }\end{array}$ & $\begin{array}{l}\text { Factor 3: } \\
\text { Developmental } \\
\text { burden }\end{array}$ & $\begin{array}{l}\text { Factor 4: } \\
\text { Emotional burden }\end{array}$ & $\begin{array}{l}\text { Factor } 5 \text { : Social } \\
\text { burden }\end{array}$ \\
\hline Item 14: I'm physically tired & 0.95 & & & & \\
\hline Item 13: Caregiving has made me physically ill & 0.94 & & & & \\
\hline Item 12: My health has suffered & 0.54 & & & & \\
\hline Item 11: I'm not getting enough sleep & 0.49 & & & & \\
\hline $\begin{array}{l}\text { Item 1: My care receiver needs my help to perform } \\
\text { many daily tasks }\end{array}$ & & 0.87 & & & \\
\hline $\begin{array}{l}\text { Item 4: I have to help my care receiver with many } \\
\text { basic functions }\end{array}$ & & 0.81 & & & \\
\hline Item 3: I have to watch my care receiver constantly & & 0.67 & & & \\
\hline $\begin{array}{l}\text { Item 5: I don't have a minute's break from my } \\
\text { caregiving chores }\end{array}$ & & 0.60 & & & \\
\hline $\begin{array}{l}\text { Item 9: I feel emotionally drained due to caring for } \\
\text { my care receiver }\end{array}$ & & & -0.96 & & \\
\hline Item 7: I wish I could escape from this situation & & & -0.86 & & \\
\hline Item 6: I feel that I'm missing out on life & & & -0.82 & & \\
\hline $\begin{array}{l}\text { Item 10: I expected that things would be different } \\
\text { at this point in my life }\end{array}$ & & & -0.57 & & \\
\hline Item 21: I feel ashamed of my care receiver & & & & 0.90 & \\
\hline $\begin{array}{l}\text { Item 20: I feel embarrassed by my care receiver's } \\
\text { behavior }\end{array}$ & & & & 0.87 & \\
\hline $\begin{array}{l}\text { Item 23: I feel uncomfortable when I have friends } \\
\text { over }\end{array}$ & & & & 0.65 & \\
\hline $\begin{array}{l}\text { Item 24: I feel angry about my reactions toward } \\
\text { my care receiver }\end{array}$ & & & & 0.39 & \\
\hline $\begin{array}{l}\text { Item 16: My caregiving efforts aren't appreciated } \\
\text { by others in my family }\end{array}$ & & & & & 0.68 \\
\hline $\begin{array}{l}\text { Item 19: I feel resentful of other relatives who } \\
\text { could but do not help }\end{array}$ & & & & & 0.56 \\
\hline Item 17: I've had problems with my marriage & & & & & 0.40 \\
\hline $\begin{array}{l}\text { Item 15: I don't get along with other family } \\
\text { members as well as I used to }\end{array}$ & & & & & 0.36 \\
\hline Explained Variance & $44.8 \%$ & $10.4 \%$ & $6.5 \%$ & $6 \%$ & $5 \%$ \\
\hline
\end{tabular}

subjects caring for disabled patients struggled with physical, emotional, financial, and social issues [21].

\section{Care recipients' and caregivers' characteristics}

The disabled subjects in this study were mainly composed of males (73.3\%), 50.2\% were illiterate, $13.9 \%$ were currently working, and 30\% were married. These figures approximate to some extent the previous figures reported about disabled subjects in Egypt (64.2\% males, 72\% illiterate, $21.1 \%$ employed, and $42.4 \%$ married) [6]. Data on the prevalence of disability in Egypt are inconclusive and do not agree with international data-sets due to differences in the disability definition, data collection methods, cultural attitudes, and tendency to hide disability in public and scarce data on diseases frequently causing disabilities [8].
The study found that the caregivers were mostly women $(87.7 \%)$ and non-working subjects (80\%). Moreover, 58\% of caregivers were illiterate. The predominance of women as caregivers corroborates the findings of previous studies [22-24] which can be explained by the tendency of women to carry out many roles, frequently including domestic work, employment, and caregiving to the family members [25]. The profiles of the caregivers in the study reveal the cultural tendency and tradition of rural communities in Egypt where participation of illiterate and nonworking women in familial caregiving is preferred, especially those who have motherhood experience. Furthermore, the majority of caregivers were parents (62.6\%) and spouses $(14.8 \%)$. These percentages coincide with some recent findings $[23,26]$ and reflects the family bonding and support in the rural areas of Egypt. 
Table 3 Total and relative CBI dimension scores according to caregivers' characteristics

\begin{tabular}{|c|c|c|c|c|c|c|}
\hline Socio-demographic characteristics & CBI total & Physical burden & $\begin{array}{l}\text { Time dependence } \\
\text { burden }\end{array}$ & Developmental burden & Emotional burden & Social burden \\
\hline \multicolumn{7}{|l|}{ Age groups } \\
\hline$<40$ years & $46.4(17.9)$ & $9(4.9)$ & $12.8(4.9)$ & $8.9(4.8)$ & $7.2(4.2)$ & $8.3(3.8)$ \\
\hline $41-60$ years & $49.7(17.3)$ & $10.1(4.8)$ & $12.7(5.1)$ & $9.1(4.9)$ & $8.4(4.2)$ & $9.4(4.4)$ \\
\hline$>60$ years & $55.9(18.3)$ & $13.4(4.5)$ & $15.5(4.6)$ & $9.3(4.9)$ & $8(4.6)$ & $9.7(3.9)$ \\
\hline P-value & 0.051 & $<0.001$ & 0.042 & 0.966 & 0.109 & 0.114 \\
\hline \multicolumn{7}{|l|}{ Sex } \\
\hline Male & $47.9(14.7)$ & $9.9(5.1)$ & $12.6(5)$ & $9.4(4.2)$ & $7.7(3.7)$ & $8.3(3.8)$ \\
\hline Female & $49.1(18.3)$ & $10(4.9)$ & $13.1(5)$ & $9(4.9)$ & $7.9(4.3)$ & $9(4.2)$ \\
\hline$P$-value & 0.736 & 0.970 & 0.596 & 0.713 & 0.752 & 0.381 \\
\hline \multicolumn{7}{|l|}{ Marital status } \\
\hline Unmarried & $48.9(17.7)$ & $9.9(4.9)$ & $13.3(5)$ & $9.1(4.8)$ & $7.8(4.2)$ & $8.9(4.2)$ \\
\hline Married & $48.8(18.9)$ & $10.1(5)$ & $12.2(5)$ & $9.1(4.9)$ & $8.5(4.4)$ & $9(3.9)$ \\
\hline P-value & 0.955 & 0.808 & 0.186 & 0.996 & 0.304 & 0.991 \\
\hline \multicolumn{7}{|l|}{ Working status } \\
\hline Not working & $49.2(18.3)$ & $10(5)$ & $13.1(5.1)$ & $9.1(4.9)$ & $7.9(4.3)$ & $9(4.1)$ \\
\hline Working & $47.2(14.7)$ & $9.6(4.5)$ & $13(4.9)$ & $8.8(4.2)$ & $7.4(3.6)$ & $8.3(4)$ \\
\hline P-value & 0.567 & 0.643 & 0.975 & 0.815 & 0.484 & 0.372 \\
\hline \multicolumn{7}{|l|}{ Education } \\
\hline Not educated & $51.5(18.4)$ & $10.7(5.1)$ & $13.6(4.9)$ & $9.6(5)$ & $8.1(4.2)$ & $9.5(4.4)$ \\
\hline Educated & $44.5(16.1)$ & $8.6(4.3)$ & $12.2(5)$ & $8.1(4.3)$ & $7.6(4.3)$ & $7.9(3.4)$ \\
\hline P-value & 0.003 & 0.001 & 0.044 & 0.020 & 0.387 & 0.004 \\
\hline \multicolumn{7}{|l|}{ Relationship to the patient } \\
\hline Spouse/partner & $51.5(19.2)$ & $10.8(5.1)$ & $13(5.1)$ & $9.3(4.9)$ & $8.5(4.6)$ & $9.8(4.4)$ \\
\hline Parent & $44.7(13.5)$ & $9.4(3.9)$ & $13.9(5.8)$ & $7.4(3.9)$ & $6(2.5)$ & $7.9(2.7)$ \\
\hline Sibling & $41.8(8.9)$ & $7.5(4.5)$ & $13.8(4.1)$ & $8.4(3.2)$ & $5.3(0.9)$ & $6.8(1.9)$ \\
\hline Other relatives & $45.8(16.2)$ & $8.6(4.5)$ & $12.7(4.8)$ & $9.1(4.9)$ & $7.5(3.9)$ & $7.9(3.6)$ \\
\hline P-value & 0.043 & 0.004 & 0.755 & 0.357 & 0.006 & 0.002 \\
\hline \multicolumn{7}{|l|}{ Duration of caregiving } \\
\hline $1-10$ years & $46.6(16.5)$ & $9.1(4.7)$ & $13.2(4.8)$ & $8.7(4.4)$ & $7.4(4)$ & $8.2(3.8)$ \\
\hline$>10$ years & $50.9(18.8)$ & $10.7(5.1)$ & $12.9(5.2)$ & $9.4(5.2)$ & $8.4(4.4)$ & $9.6(4.3)$ \\
\hline$P$-value & 0.055 & 0.014 & 0.657 & 0.254 & 0.064 & 0.007 \\
\hline \multicolumn{7}{|l|}{ Family income } \\
\hline Not/hardly enough & $50.11(18.1)$ & $10.3(5.1)$ & $13.3(4.9)$ & $9.3(4.9)$ & $8.1(4.3)$ & $9.1(4.2)$ \\
\hline Enough & $38.4(10.9)$ & $7.2(2.7)$ & $10.8(5.2)$ & $6.9(3.4)$ & $6.1(2.3)$ & $7.4(2.8)$ \\
\hline P-value & $<0.001$ & 0.003 & 0.020 & 0.004 & 0.001 & 0.007 \\
\hline Total & $48.9(17.9)$ & $9.9(4.9)$ & $13.1(5)$ & $9.1(4.8)$ & $7.9(4.2)$ & $8.9(4.1)$ \\
\hline
\end{tabular}

The data was presented as mean (SD)

\section{$\mathrm{CBI}$ as a measure of caregiver burden}

The CBI questionnaire does not only quantify the global burden, but also evaluates different aspects of the burden through its subscales. The CBI has already been used in different caregiver populations [26-28] including among patients with physical, mental, and mixed disabilities [29]. This study included EFA to determine the factor structure of $\mathrm{CBI}$ among the study population. EFA is suitable for assessing interesting latent constructs as was intended in this study rather than to test a specific hypothesis [30]. Also, the collected data of the study was the interval level which was appropriate for EFA. Moreover, EFA accounts for measurement error and helps to result in more realistic assumptions [31] than 
Table 4 Total and relative CBI dimension scores according to care recipients' characteristics

\begin{tabular}{|c|c|c|c|c|c|c|}
\hline Socio-demographic characteristics & CBI total & $\begin{array}{l}\text { Physical } \\
\text { burden }\end{array}$ & Time dependence burden & $\begin{array}{l}\text { Developmental } \\
\text { burden }\end{array}$ & Emotional burden & Social burden \\
\hline \multicolumn{7}{|l|}{ Age groups } \\
\hline$<18$ years & $51.3(18.5)$ & $10.9(5)$ & $12.9(5.1)$ & $10(5.1)$ & $8(4.3)$ & $9.4(4.4)$ \\
\hline $19-40$ years & $48.9(18.5)$ & $9.9(4.9)$ & $12.8(5.1)$ & $8.7(4.8)$ & $8.2(4.6)$ & $9.3(4.2)$ \\
\hline $41-60$ years & $47.7(18.7)$ & $9.4(5.2)$ & $13.1(5.2)$ & $9.2(4.8)$ & $8(3.9)$ & $8(3.2)$ \\
\hline$>60$ years & $44.7(11.3)$ & $8.4(4.3)$ & $14.3(4.3)$ & $8.4(4.1)$ & $6(2.2)$ & $7.6(3.4)$ \\
\hline$P$-value & 0.415 & 0.117 & 0.562 & 0.285 & 0.083 & 0.110 \\
\hline \multicolumn{7}{|l|}{ Sex } \\
\hline Male & $49.7(18.2)$ & $10.3(4.9)$ & $12.9(5.2)$ & $9.1(4.9)$ & $8(4.3)$ & $9.3(4.2)$ \\
\hline Female & $46.8(16.8)$ & $8.9(4.8)$ & $13.4(4.5)$ & $9(4.7)$ & $7.6(4.1)$ & $7.9(3.7)$ \\
\hline P-value & 0.263 & 0.055 & 0.541 & 0.952 & 0.448 & 0.001 \\
\hline \multicolumn{7}{|l|}{ Marital status } \\
\hline Unmarried & 49.7 (19.4) & $9.8(5.1)$ & $13(5.2)$ & $9.2(5.1)$ & $8.6(4.7)$ & $9.2(4.3)$ \\
\hline Married & $44.6(13.3)$ & $9.3(4.4)$ & $12.9(4.9)$ & $7.9(3.9)$ & $6.5(2.7)$ & $8(3.3)$ \\
\hline P-value & 0.035 & 0.466 & 0.848 & 0.069 & $<0.001$ & 0.043 \\
\hline \multicolumn{7}{|l|}{ Working status } \\
\hline Not working & $49.9(18.1)$ & $9.9(5.1)$ & $13.7(4.7)$ & $9.3(5.2)$ & $8(4.4)$ & $9(4.1)$ \\
\hline Working & $44.4(15.9)$ & $9(4.3)$ & $11.9(5.4)$ & $7.8(3.8)$ & $7.3(3.8)$ & $8.3(3.8)$ \\
\hline P-value & 0.032 & 0.188 & 0.016 & 0.033 & 0.263 & 0.249 \\
\hline \multicolumn{7}{|l|}{ Education } \\
\hline Not educated & $51.1(17.5)$ & $10.2(4.8)$ & $14.2(4.7)$ & $9.5(4.9)$ & $7.9(4.4)$ & $9.3(4.3)$ \\
\hline Educated & $46.6(18.1)$ & $9.7(5.1)$ & $11.8(5.1)$ & $8.6(4.7)$ & $7.8(4.1)$ & $8.6(3.9)$ \\
\hline P-value & 0.049 & 0.475 & $<0.001$ & 0.191 & 0.815 & 0.190 \\
\hline \multicolumn{7}{|l|}{ Type of disability } \\
\hline Hearing/visual & $40.6(11.2)$ & $8.2(3.7)$ & $11.5(4.6)$ & $7.2(3.6)$ & $6.4(2.3)$ & $7.4(2.7)$ \\
\hline Physical & $45.2(13.7)$ & $9.6(4.5)$ & $12.7(4.8)$ & $8.1(3.7)$ & $6.7(2.9)$ & $8.1(3.5)$ \\
\hline Mental & $53.9(21.5)$ & 10.9 (5.8) & $13.2(5.3)$ & $10.3(5.5)$ & $9.4(5.2)$ & $10.1(4.4)$ \\
\hline Mixed & $59.8(19.5)$ & $11.6(5.3)$ & $15.5(4.8)$ & $11.6(5.8)$ & $10(5.3)$ & $11(4.9)$ \\
\hline$P$ value & $<0.001$ & 0.003 & 0.001 & $<0.001$ & $<0.001$ & $<0.001$ \\
\hline
\end{tabular}

The data was presented as mean (SD)

the principal component analysis that was performed by Marvardi et al. [28]. Both the global scale and its different dimensions proved to be very reliable, as shown by the high alpha co-efficient. On the CBI scale, caregivers scored much higher on the time-dependent burden subscale compared with other subscales and the emotional burden domain showed the lowest score. These findings are consistent with the results of previous studies, which noted that the time spent on caregiving, together with the lack of sufficient personal time for the caregiver were the most important variables related to the burden of caregivers [32-34]. Similarly, Bartolo et al. [23] found that feelings of being ashamed of or embarrassed by the patient seemed to account for a smaller part of the burden.

\section{Determinants of caregiver burden}

The study results support the finding that caregiver and care recipient characteristics may play an important role in determining the burden of care. We found that the total burden of care was associated with caregiver education and family income. Moreover, family income was associated with most subdimensions of burden. Having enough family income was associated with reduced physical, time dependence, developmental and total burden in this study. This result was consistent with previous research findings $[21,22]$ as higher household income is expected to lead to better living conditions and consequently a better quality of life and reduced burden of care [35]. 
Table 5 Multivariate analyses of correlates of CBI scores

\begin{tabular}{|c|c|c|c|c|}
\hline Dependent variables and significantly associated variables & Unstandardized Beta & Standardized Beta & T & $P$-value \\
\hline \multicolumn{5}{|l|}{ Dependent variable: total CBI burden } \\
\hline Caregiver education (educated) & -4.86 & -0.14 & -2.05 & 0.042 \\
\hline Family income (enough) & -12.35 & -.021 & -3.21 & 0.002 \\
\hline Mental disability & 11.82 & 0.26 & 3.86 & $<0.001$ \\
\hline Mixed disability & 13.74 & 0.29 & 4.31 & $<0.001$ \\
\hline \multicolumn{5}{|l|}{ Dependent variable: Physical burden } \\
\hline Age of caregiver & 0.098 & 0.29 & 4.22 & $<0.001$ \\
\hline Family income (enough) & -3.06 & -0.19 & -2.76 & 0.006 \\
\hline \multicolumn{5}{|l|}{ Dependent variable: Time dependence burden } \\
\hline Family income (enough) & -3.67 & -0.22 & -3.16 & 0.002 \\
\hline Care-recipient education (educated) & -1.32 & -0.13 & -1.77 & 0.071 \\
\hline Care-recipient work (working) & -3.13 & -0.21 & -2.87 & 0.005 \\
\hline Age of care-recipient & 0.05 & 0.18 & 2.27 & 0.023 \\
\hline Hearing/visual disability & -2.56 & -0.21 & -2.78 & 0.006 \\
\hline \multicolumn{5}{|l|}{ Dependent variable: Developmental Burden } \\
\hline Caregiver education (educated) & -1.52 & -0.16 & -2.24 & 0.022 \\
\hline Family income (enough) & -3.02 & -0.19 & -2.79 & 0.006 \\
\hline Mental disability & 3.46 & 0.32 & 4.51 & $<0.001$ \\
\hline Mixed disability & 3.63 & 0.26 & 3.71 & $<0.001$ \\
\hline \multicolumn{5}{|l|}{ Dependent variable: Emotional burden } \\
\hline Mental disability & 3.65 & 0.38 & 5.58 & $<0.001$ \\
\hline Mixed disability & 3.75 & 0.30 & 4.42 & $<0.001$ \\
\hline \multicolumn{5}{|l|}{ Dependent variable: Social burden } \\
\hline Relationship to the patients (being a parent) & 2.13 & 0.27 & 3.78 & $<0.001$ \\
\hline
\end{tabular}

Caregiver education affected the developmental and total burden in the study participants. A previous study showed that caregivers who are less educated, unemployed, and caring for patients for a longer duration of illness had a lower quality of life [36]. This could be attributed to the fact that better-educated caregivers would have more resources available to manage the care situation and those who had a paid job outside the house are not always available to provide full-time primary care. Caregiver age was associated with the physical burden which was supported by the previous finding which stated that older caregivers experience higher burden and greater impact on their quality of life [22,37]. However, in contrast with Zahid and Ohaeri [38] who found that spouse caregivers reported more burden than other caregivers, we found that being a parent for a disabled person was significantly associated with increased social dimension burden.

Care-recipient characteristics including younger age, literacy, work, and having a hearing or visual impairment were associated with lower time-dependence burden. This finding was expected because disabled subjects who are educated or employed are expected to be more independent in a way that reduces the stress caused by the restriction of caregiver's personal time.

The current study found that mental and mixed disabilities were associated with an increase in overall burden, developmental, and emotional burden. In accordance with our findings, a previous study showed that both the burden and the quality of life were significantly worse for caregivers who care for patients with both physical and mental diseases [29]. The study finding can be explained by the fact that mental and mixed disabilities include low levels of functional abilities of patients and distress due to behavioral disturbances. This means that the more physically disabled, cognitively impaired, and disturbed the patients are, the more time, emotional effects, physical and mental energy are spent taking care of them.

Other variables such as the patient's gender and marital state, did not explain the variance of the burden of care (total and subscales) which corroborates the finding of previous studies [28]. On the other hand, statistically significant differences in caregiver burden were previously observed with the gender among spinal cord injury patients [26] and schizophrenia patients [37]. These 
differences in the results may be due to cultural and social factors variations between different countries that may affect the burden of care. Duration of care was not associated with the caregiver burden in the literature [21, 23] including our study as family caregivers for disabled subjects may undergo a process of psychosocial adaptation over the years, develop better care strategies, and have a less negative perception of the situation [39].

\section{Strengths and limitations}

This study is novel in several ways including the population and the analytic methodology that we used. Most notably, previous studies about the caregiver burden of disabled persons reported the results of developed countries' research and there is a lack of data from the Middle East region and low-income countries. Moreover, EFA suggested that only four questions were enough to investigate each dimension of $\mathrm{CBI}$ with the possibility to develop a reliable shorter form from CBI. However, confirmatory factor analysis should be considered in future studies to establish the construct validity of the shorter form. Furthermore, the researchers tried to minimize the interviewer bias by using the same clearly written questionnaire that were comprised of fixed-choice answers with no open-ended questions for all the study subjects. Also, keeping the questionnaire and interview language simple helped the interviewers to avoid further long explanation. The major limitation of the study is the cross-sectional design that is prone to selection bias. However, the systematic random sampling technique can help to achieve the goal of having a representative sample and reduce the possibility of bias. Additionally, persons with disabilities represent a heterogeneous group with respect to disability type and degree of severity. However, our study did not address this issue in detail which can affect the level of burden. Therefore, there is a need for future large scale studies for each type of impairment to determine the caregiver burden related to the type and severity of the disability.

\section{Conclusion}

The study results highlight the suffering of caregivers in terms of the burden of care provided to disabled patients. CBI proved to be an effective multidimensional scale to measure the burden of care on different aspects of caregivers' lives. Caregiver education, family income, mental impairments, and mixed disabilities were the significant predictors of total CBI burden. Support and counseling services should, therefore, be optimized, taking account of the socioeconomic conditions so that solutions tailored to caregivers' individual circumstances are provided.

\section{Abbreviations}

CBI: Caregiver Burden Inventory; EFA: Exploratory factor analysis

\section{Acknowledgments}

Not applicable.

\section{Authors' contributions}

EG and MA analyzed and interpreted the data after collection by a team of three investigators and were major contributors in writing the manuscript. ESM and EM helped in writing the research paper. All authors read and approved the final manuscript.

\section{Funding}

Not applicable.

\section{Availability of data and materials}

The datasets used and/or analyzed during the current study are available from the corresponding author on reasonable request.

\section{Ethics approval and consent to participate}

The study protocol was approved by the Ethical Committee of Faculty of Medicine, Minia University on 8 August 2019 (No. 19815). Informed verbal consent was obtained from all participants of the study which was approved by the ethics committee due to high rate of illiteracy among the rural residents. Confidentiality and anonymity of the participants were strictly maintained through a code number on the questionnaire.

\section{Consent for publication}

Not applicable.

\section{Competing interests}

The authors declare that they have no competing interests.

Received: 4 March 2020 Accepted: 15 July 2020

Published online: 23 July 2020

\section{References}

1. World Health Organization. Disability and health. Geneva: WHO; 2018. www. who.int/news-room/fact-sheets/detail/disability-and-health Accessed 11 Dec 2019.

2. United Nations. UN convention on the rights of persons with disabilities. 2006. https://www.un.org/disabilities/documents/convention/convoptprot-e. pdf Accessed 15 Dec 2019.

3. Watson N. Well, I know this is going to sound very strange to you, but I don't see myself as a disabled person: identity and disability. Disabil Soc. 2002;17:509-27.

4. Misra S, Orslene LE, Walls RT. Personal assistance services (PAS) for workers with disabilities: views and experiences of employers. J Rehabil. 2010;76(1): 22-7.

5. Danquah L, Polack S, Brus A, Mactaggart I, Houdon CP, Senia P, et al. Disability in post-earthquake Haiti: prevalence and inequality in access to services. Disabil Rehabil. 2015;37:1082-9.

6. Economic and Social Commission of Western Asia, League of Arab States. Disability in the Arab region - an overview. Beirut: United Nations; 2014 https://socialprotectionhumanrights.org/wpcontent/uploads/2015/08/ Disabilit_Arab_region_2014.pdf Accessed 15 Dec 2019.

7. World Health Organization and World Bank. World report on disability. Geneva: WHO; 2011. https://www.who.int/disabilities/world_report/2011/ report.pdf Accessed 30 Dec 2019.

8. Gutenbrunner C, Nugraha B. Responding to the world health organization global disability action plan in Egypt: a technical consultation to develop a national disability, health and rehabilitation plan. J Rehabil Med. 2018;50: 333-7.

9. Goldner M, Drentea P. Caring for the disabled: applying different theoretical perspectives to understand racial and ethnic variations among families. Marriage Fam Rev. 2009:45:499-518.

10. Grunfeld E, Coyle D, Whelan T, Clinch J, Reyno L, Earle C, et al. Family caregiver burden: results of a longitudinal study of breast cancer patients and their principal caregivers. CMAJ. 2004;170:1795-801. 
11. Oliveira EF, Limongi SCO. Quality of life of parents/caregivers of children and adolescents with Down syndrome. J Soc Bras Fonoaudiol. 2011;23: $321-7$.

12. Jeong $Y G$, Myong JP, Koo JW. The modifying role of caregiver burden on predictors of quality of life of caregivers of hospitalized chronic stroke patients. Disabil Health J. 2015;8:619-25.

13. Gull M, Nizami N. Comparative study of hope and psychological well-being among the parents of physically and intellectually disabled children. Int J Mod Soc Sci. 2015:4(42):143-52.

14. Murphy NA, Christian B, Caplin DA, Young PC. The health of caregivers for children with disabilities: caregiver perspectives. Child Care Health Dev. 2007;33:180-7.

15. Braccialli LMP, Bagagi PS, Sankako AN, Araújo RCT. Qualidade de Vida de cuidadores de pessoas com necessidades especiais. Rev Bras Ed Esp. 2012; 18:113-26.

16. Vitaliano PP, Young HM, Russo J. Burden: a review of measures used among caregivers of individuals with dementia. Gerontologist. 1991;31:67-75.

17. van Exel NJ, Scholte op Reimer WJ, Brouwer WB, van den Berg B, Koopmanschap MA, van den Bos GA. Instruments for assessing the burden of informal caregiving for stroke patients in clinical practice: a comparison of CSI, CRA, SCQ and self-rated burden. Clin Rehabil. 2004:18:203-14.

18. Schulze B, Rössler W. Caregiver burden in mental illness: review of measurement, findings and interventions in 2004-2005. Curr Opin Psychiatry. 2005;8:684-91

19. Novak M, Guest C. Application of a multidimensional caregiver burden inventory. Gerontologist. 1989;29:798-803.

20. Caserta MS, Lund DA, Wright SD. Exploring the caregiver burden inventory (CBI): further evidence for a multidimensional view of burden. Int J Aging Hum Dev. 1996;43:21-34.

21. Muller-Kluits N, Slabbert I. Caregiver burden as depicted by family caregivers of persons with physical disabilities. Soc Work. 2018;54:493-502.

22. Barros ALO, de Gutierrez GM, Barros AO, Santos M. Quality of life and burden of caregivers of children and adolescents with disabilities. Spec Care Dentist. 2019:39:380-8.

23. Bartolo M, De Luca D, Serrao M, Sinforiani E, Zucchella C, Sandrini G. Caregivers burden and needs in community neurorehabilitation. J Rehabil Med. 2010;42:818-22.

24. Caro CC, Costa JD, Da Cruz DMC. Burden and quality of life of family caregivers of stroke patients. Occup Ther Health Care. 2018;32:154-71.

25. Jacques HAK. Young women constructing identities: Multiple subject positions and the superwoman ideal, University of Calgary. Ottawa: Library and Archives of Canada. 2008. Available at: https://www.worldcat.org/title/ young-women-constructing-identities-multiple-subject-positions-and-thesuperwomanideal/oclc/669240946\&referer=brief_results.

26. Maitan P, Frigerio S, Conti A, Clari M, Vellone E, Alvaro R. The effect of the burden of caregiving for people with spinal cord injury (SCI): a crosssectional study. Ann Ist Super Sanita. 2018;54(3):185-93.

27. Greco A, Pancani L, Sala M, Annoni AM, Steca P, Paturzo M, et al. Psychometric characteristics of the caregiver burden inventory in caregivers of adults with heart failure. Eur J Cardiovasc Nurs. 2017;16(6):502-10.

28. Marvardi M, Mattioli P, Spazzafumo L, Mastriforti R, Rinaldi P, Polidori MC, et al. The caregiver burden inventory in evaluating the burden of caregivers of elderly demented patients: results from a multicenter study. Aging Clin Exp Res. 2005;17:46-53.

29. Settineri S, Rizzo A, Liotta M, Mento C. Caregiver's burden and quality of life: caring for physical and mental illness. Int J Psychol Res. 2014;7:30-9.

30. Fabrigar LR, Wegener DT, MacCallum RC, Strahan EJ. Evaluating the use of exploratory factor analysis in psychological research. Psychol Methods. 1999; 4:272-99.

31. Loehlin JC. Component analysis versus common factor analysis: a case of disputed authorship. Multivariate Behav Res. 1990;25:29-31.

32. Bakas T, Austin JK, Jessup SL, Williams LS, Oberst MT. Time and difficulty of tasks provided by family caregivers of stroke survivors. J Neurosci Nursing 2004;36:95-106.

33. Papastavrou E, Kalokerinou A, Papacostas SS, Tsangari H, Sourtzi P. Caring for a relative with dementia: family caregiver burden. J Adv Nurs. 2007;58: 446-57.

34. Miyashita M, Narita Y, Sakamoto A, Kawada N, Akiyama M, Kayama M, et al. Care burden and depression in caregivers caring for patients with intractable neurological diseases at home in Japan. J Neurol Sci. 2009;276: $148-52$.
35. LA Nickel R, Navarro EJ, Pinto LM, Teive HAG, Becker N. Correlation between the caregivers' quality of life and family levels of functional independence of care. Cogitare Enferm. 2010;15:225-30.

36. Alshubaili AF, Ohaeri JU, Awadalla AW, Mabrouk AA. Family caregiver quality of life in multiple sclerosis among Kuwaitis: a controlled study. BMC Health Serv Res. 2008:8:206.

37. Kumar CN, Suresha KK, Thirthalli J, Arunachala U, Gangadhar BN. Caregiver burden is associated with disability in schizophrenia: results of a study from a rural setting of south India. Int J Soc Psychiatry. 2015;61:157-63.

38. Zahid MA, Ohaeri JU. Relationship of family caregiver burden with quality of care and psychopathology in a sample of Arab subjects with schizophrenia. BMC Psychiatry. 2010;10:71

39. Ferreira MC, Di Naccio BL, Otsuka MYC, Barbosa AM, Corrêa PFL, Gardenghi $\mathrm{G}$. Assessing the burden on primary caregivers of children with cerebral palsy and its relation to quality of life and socioeconomic aspects. Acta Fisiatr. 2015;22:9-13.

\section{Publisher's Note}

Springer Nature remains neutral with regard to jurisdictional claims in published maps and institutional affiliations.
Ready to submit your research? Choose BMC and benefit from:

- fast, convenient online submission

- thorough peer review by experienced researchers in your field

- rapid publication on acceptance

- support for research data, including large and complex data types

- gold Open Access which fosters wider collaboration and increased citations

- maximum visibility for your research: over $100 \mathrm{M}$ website views per year

At $\mathrm{BMC}$, research is always in progress.

Learn more biomedcentral.com/submissions 